\title{
Aspectos geológicos e geomorfológicos da Cachoeira de Casca D'Anta (Parque Nacional da Serra da Canastra - Minas Gerais, Brasil): primeiros passos para o seu aproveitamento geoturístico
}

\author{
Geological and geomorphological aspects of the Casca D'Anta \\ Waterfall (Canastra's Ridge National Park, Minas Gerais, \\ Brazil): first steps to its geoturistic approach
}

Lilian Carla Moreira Bento, Labgeol, Instituto de Ciências Humanas do Pontal, Universidade Federal de Uberlândia, Brasil, liliancmb@ufu.br

(1) https://orcid.org/0000-0003-0916-9585

Sílvio Carlos Rodrigues, Lages, Instituto de Geografia, Universidade Federal de Uberlândia, Brasil, silgel@ufu.br

(D) http://orcid.org/0000-0002-5376-1773

Resumo: A Cachoeira de Casca D'Anta está localizada na escarpa sul da Serra da Canastra, no estado de Minas Gerais (Brasil), onde nasce um dos rios mais importantes do país, o Rio São Francisco. Compreende uma queda com 200 metros de desnível, esculpida em quartzitos do Grupo Canastra. É um dos atrativos mais visitados do Parque Nacional da Serra da Canastra (PARNA Serra da Canastra), unidade de conservação do tipo integral. Apesar de ser uma área de proteção que permite a visitação, não existe no parque um programa de educação e interpretação ambiental que aborde o patrimônio geomorfológico. Nesse sentido, tendo em visto essa carência e o fato da Casca D'anta ser um dos atrativos mais visitados no parque, o objetivo deste trabalho é apresentar um levantamento científico no que diz respeito aos aspectos geológicos e geomorfológicos da área, de modo a compreender a origem e evolução dessa feição. De posse dessas informações, num segundo momento, espera-se subsidiar a proposição de um painel interpretativo para que os visitantes passem a associar o aspecto contemplativo ao educativo, superando a subutilização do local do ponto de vista pedagógico e de valorização do patrimônio geomorfológico, indo ao encontro dos objetivos da prática do Geoturismo.

Palavras-chave: Queda d'água; Conhecimento; Ciência; Educação; Valorização; Geoturismo.

Abstract: The Casca D'Anta Waterfall is located on the southern escarpment of Serra da Canastra, in the state of Minas Gerais (Brazil), where one of the most important rivers of the country, the São Francisco River, is born. It comprises a fall with 200 meters of unevenness, carved in quartzite of the Canastra Group. It is one of the most visited attractions of the Serra da Canastra National Park (PARNA Serra da Canastra), an integral conservation unit. Despite of being a protection area that allows visitors, there is no environmental education and interpretation program in the park that addresses the geomorphological heritage. In this sense, considering this lack and the fact that Casca D'Anta is one of the most visited attractions in the park, the objective of this work is to present a scientific survey regarding the geological and geomorphological aspects of the area, in order to understand the origin and evolution of this feature. With this information, secondly, it is hoped to subsidize the proposition of an interpretative panel so that the visitors will be able to begin to associate the contemplative aspect with the educative aspect, overcoming the underutilization of the place from the pedagogical point of view and the valorization of the geomorphological heritage facing the objectives of the practice of Geotourism.

Keywords: Waterfall; Knowledge; Science; Education; Valorization; Geotourism. 


\section{Introdução}

A Cachoeira de Casca D'Anta, queda com 200 metros de desnível e esculpida em quartzitos, está localizada na escarpa sul da Serra da Canastra, no Parque Nacional da Serra da Canastra (PARNA Serra da Canastra). Esse parque se localiza no sudeste de Minas Gerais e abrange os municípios de São Roque de Minas, Sacramento, Delfinópolis, São João Batista do Glória, Capitólio e Vargem Bonita (Figura 1). Sua área total é de 197.787 hectares, no entanto, a mesma não foi totalmente regularizada e a parte com situação fundiária regular totaliza apenas 71.525 hectares.

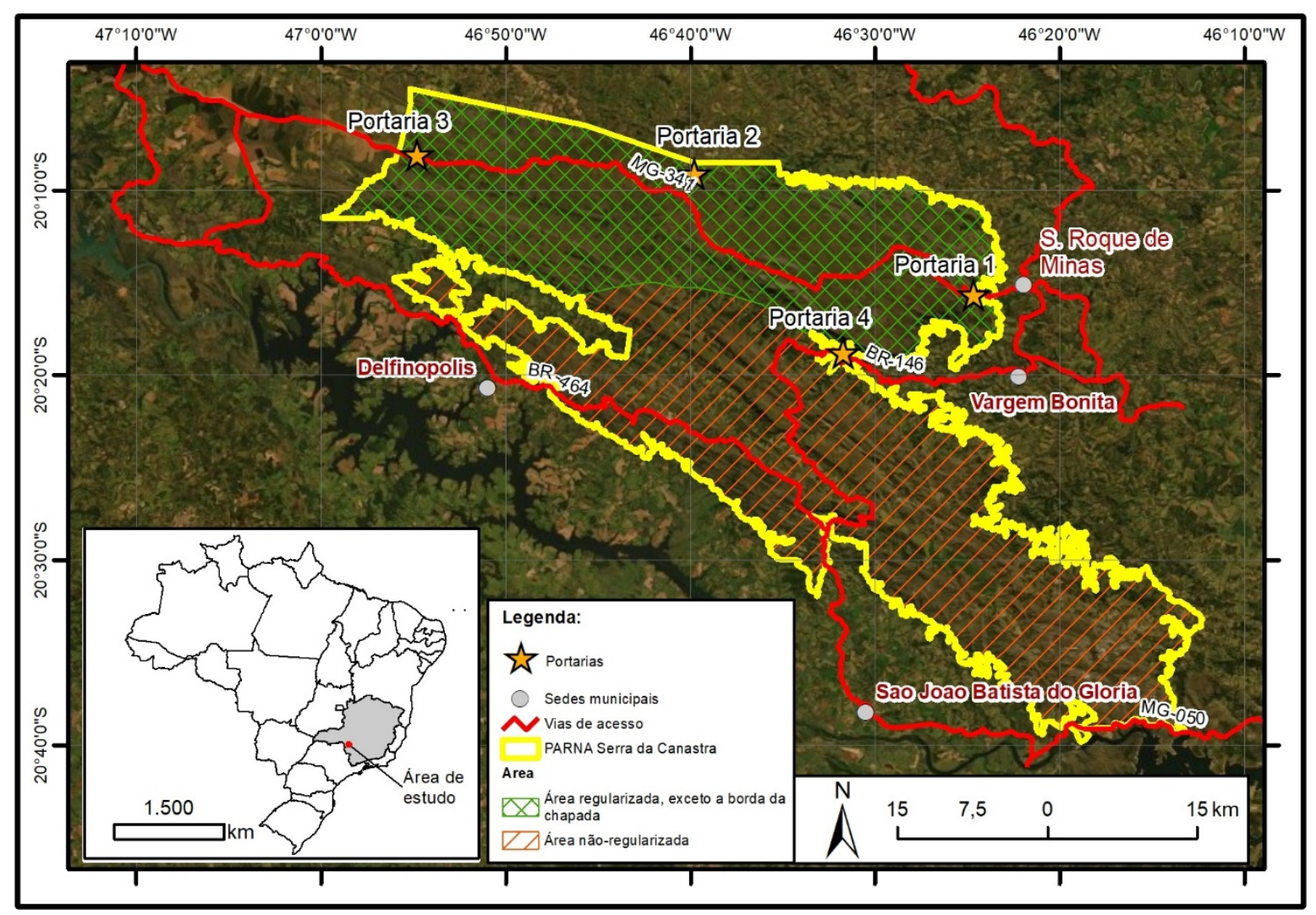

Figura 1: Mapa de localização da área de estudo.

O título deste trabalho é "Aspectos geológicos e geomorfológicos da Cachoeira de Casca D'anta (Parque Nacional da Serra da Canastra - Minas Gerais, Brasil): primeiros passos para o seu aproveitamento geoturístico" e já indica uma relação entre os aspectos geológico-geomorfológicos e o geoturismo, mas qual é éssa relação? E, ainda, o que vem a ser esse tal de geoturismo?

Para entender o conceito, a importância do geoturismo e sua relação com os aspectos acima citados, é fundamental entendermos antes outros conceitos, tais como geodiversidade, geopatrimônio e patrimônio geomorfológico. O meio ambiente pode ser dividido, de modo geral, em uma vertente biótica e outra abiótica. A Geodiversidade engloba esta última, bem como toda a sua diversidade e os processos que foram necessários para a sua existência e evolução ao longo do tempo geológico. 
Pode ser entendida numa escala espacial, tendo-se os mineirais, as rochas, os solos, o relevo, as paisagens como os elementos representativos, além de outros, tais como os fósseis, a água etc. (Bento, 2014).

Assim como a Biodiversidade, a Geodiversidade também tem sua importância, a qual pode ser avaliada mediante os seus valores, a saber: intrínseco, cultural, científico, funcional, estético e econômico (Gray, 2005, 2011); e serviços ambientais: regulação, suporte, provisão e conhecimento (Silva, Mansur, Nascimento, 2018).

Dada a importância da Geodiversidade e, ao mesmo tempo, a impossibilidade de sua proteção total, Carcavilla, Durán e Lopéz-Martinez (2008) explicam que foi elaborado um conceito que abrange porções dessa geodiversidade com valores significativos, denominados de geossítios ou sítios geológicos e os quais deveriam ser alvos de medidas de (geo) conservação e, ao conjunto desses sítios, dá-se o nome de Geopatrimônio. Geopatrimônio pode, portanto, ser considerado um conceito "guardachuva", uma vez que abarca o conjunto abrangente e complexo das múltiplas possibilidades de elementos abióticos, como os geológicos, geomorfológicos, hidrológicos, mineiro, entre muitos outros, dotados de valor, principalmente, do ponto de vista científico, cultural ou turístico (Brilha, 2005).

Apesar da proposição do termo Geopatrimônio para todos os tipos de patrimônio natural abiótico, alguns autores acham mais viável fazer a individualização, de forma a direcionar melhor as estratégias de proteção. Vieira e Lúcio (2004), por exemplo, argumentam que o patrimônio geomorfológico envolve as formas de relevo e os depósitos correlativos, podendo ser pequenos ou grandes, isolados ou formando conjuntos.

Isso posto, resta-nos entender o que é o Geotursimo. Este deve ser encarado como uma prática turística que visa suprir uma lacuna deixada pelo ecoturismo, no sentido de que, na realidade, este último aborda apenas a Biodiversidade, negligenciando os elementos da Geodiversidade. Além disso, é uma atividade que busca conciliar a contemplação, típica do turismo, com o entendimento do local visitado, imprimindo uma preocupação com o local alvo da visita e podendo ser inserido num viés mais sustentável. Esse entendimento pode ser obtido através de meios interpretativos, seja do tipo personalizado, com a presença de guias ou monitores, ou não personalizado, com placas ou painéis, por exemplo. Segundo Bento e Rodrigues (2013), a interpretação ambiental visa a sensibilização das pessoas de uma forma lúdica, mediante uma linguagem acessível ao público leigo, de maneira a se oportunizar mudanças de comportamentos que induzam a atitudes pró-ambiente. Tal proposta se baseia em Tilden (1957), grande precursor da interpretação ambiental, que dizia que a proteção pode ser obtida a partir da interpretação, pois há o estímulo para se compreender os locais e dessa compreensão surge a apreciação e, por último, o sentimento e a necessidade de se cuidar, resguardar esses locais.

Nesse sentido, tem-se que o geoturismo só pode ser implantado de fato a partir de um minucioso estudo da Geodiversidade do lugar, sendo de suma importância o entendimento, no mínimo, dos aspectos geológicos e geomorfológicos, os quais 
acabam subsidiando na compreensão dos demais elementos abióticos. $O$ conhecimento científico, nesse caso, pode tanto contribuir para a interpretação da origem e evolução das paisagens, como também dos seus limites e potencialidades, contribuindo para o planejamento da atividade turística (Boas, Marçal, 2014).

No caso da interpretação ambiental, Bento (2014) ressalta que, apesar do seu viés educativo, ela não deve ser confundida com educação ambiental, já que, ao contrário desta última, é uma atividade pontual voltada à sensibilização do visitante através de uma tradução das paisagens, pois os ambientes naturais não falam por si. Sendo assim, deve ser encarada apenas como um instrumento da educação ambiental, visto que proporciona conhecimento sobre alguma coisa e visa à mudança de comportamentos considerados ambientalmente incorretos.

O objetivo deste trabalho é apresentar um levantamento científico no que diz respeito aos aspectos geológicos e geomorfológicos da área, de modo a compreender a origem e evolução da Cachoeira de Casca D'anta, um dos atrativos mais visitados no parque (Bizerril, Soares, Santos, 2008), no intuito de, futuramente, subsidiar o seu aproveitamento geoturístico mediante a instalação de painéis interpretativos.

Tem-se como justificativa três aspectos principais, a saber: i- Mauro e Valadão (2018) identificaram que, apesar do PARNA Serra da Canastra ser uma das unidades de conservação mais pesquisadas no Brasil, $83 \%$ do conhecimento gerado está associado a biodiversidade. Tal realidade levanta a necessidade de pesquisas voltadas à geodiversidade da área, até mesmo porque se existe uma grande diversidade biológica o elemento norteador é a geologia; ii- apesar de ser uma área de proteção que permite a visitação, não existe um programa de educação e interpretação ambientais voltados ao patrimônio geomorfológico e; iii- o geoturismo é uma prática que direciona o olhar dos visitantes para os aspectos da geodiversidade, buscando o seu entendimento mediante meios interpretativos contribuindo, portanto, para sua valorização e conservação.

Por se tratar de um trabalho teórico, a metodologia empregada envolveu o levantamento e fichamento de obras pertinentes ao tema, a partir de dois eixos temáticos principais, um voltado aos aspectos geológicos e geomorfológicos da área de estudo (se priorizou apenas os aspectos da área regularizada no parque) e outro sobre geopatrimônio e geoturismo. O levantamento se deu, principalmente, a partir da busca de palavras-chaves em sites como Researchgate, Scielo, Portal da Capes, Biblioteca Digital Brasileira de Teses e Dissertações (BDTD), Redalyce Google acadêmico.

\section{Resultados}

Quedas d'água são formas de relevo geradas em ambiente fluvial, são rupturas do leito do rio que ocorrem em função de um desnível topográfico. Levando em consideração o aspecto genético, podem ser do tipo construtivas ou destrutivas (Bento, 2010). O entendimento de sua formação está atrelado a um contexto mais 
amplo que é o de se compreender as unidades litológicas, bem como a história geológica que está por trás desse cenário.

A gênese da Cachoeira de Casca D'anta está associada a existência de uma falha de empurrão de direção NW-SE que sobrepõe unidades geológicas antigas sobre mais recentes (Chaves, Benitez, Andrade, 2012) e que originou no relevo um degrau por onde a água do rio São Francisco despenca verticalmente e forma uma feição de grande beleza cênica e que já chamava atenção dos naturalistas, o que pode ser comprovado no livro "Em Viagem às nascentes do rio São Francisco", de Saint-Hilaire (1975).

A existência dessa falha é um dos resultados da longa história geológica à qual a região foi submetida, refletindo a ação dos agentes geológicos internos e externos. Nesse sentido, tendo em vista que o levantamento científico aqui exposto representa os primeiros passos para o aproveitamento geoturístico da área, os resultados abaixo foram estruturados de tal forma a possibilitar o entendimento dos aspectos geológicoestruturais e do relevo, analisando a dinâmica interna e externa no viés do tempo geológico.

Quando olhamos a configuração atual do território brasileiro é difícil imaginar que nem sempre foi assim. O que hoje é o Brasil já esteve localizado em outras latitudes e longitudes, além de ora estar emerso ora estar submerso em águas oceânicas (Bento, 2018). Nesse sentido, o entendimento de qualquer feição geomorfológica demanda entender que as duas forças naturais que atuam sobre o planeta, uma interna, comandada pela tectônica de placas e a outra externa, ditada, principalmente, pelo clima, o fizeram em diferentes escalas de tempo e espaço.

Do ponto de vista interno, como a crosta terrestre é dividida em placas que estão em constante deriva em função das correntes de convecção do magma, os continentes registraram, ao longo do tempo geológico, uma gama variada de posições geográficas (latitudes maiores ou menores), formando pequenos ou grandes continentes, neste último caso denominados de supercontinentes, como o Kenorano, Colúmbia, Rodínia, Pannotia, Gondwana e Pangea, por exemplo. A separação ou junção litosférica recebe o nome de Ciclos Tectônicos e, para o Brasil, se consideram os seguintes ciclos: Jequié=Rio das Velhas, Transamazônico, Sunsas, Cariris Velhos, Brasiliano e Ciclo atual (Hasui, 2012). Relevante destacar que a crosta não se movimenta apenas horizontalmente, há também movimentos verticais, geralmente mais lentos, e que ocorrem no interior das placas, denominados de epirogênese e responsáveis, entre outros, pela formação de falhas geológicas as quais interferem na drenagem dos cursos d'água e na formação de quedas.

Externamente, o planeta é esculpido pelos agentes comandados pelo clima e este também oscilou ao longo do tempo geológico, com alternância de fases quentes e frias. Penteado (1978) explica que essa oscilação se deu ao longo da história da Terra, períodos muito quentes (devoniano, jurássico e eoceno) alternados com períodos muito frios (cambriano, carbonífero e quaternário). Essas oscilações afetaram a dinâmica do ciclo hidrológico, geraram abaixamento ou aumento do nível do mar e 
tudo isso interfere nos processos de erosão, transporte e sedimentação dominantes; em épocas mais secas prevalece a erosão mecânica e a formação de superfícies mais planas e, em contrapartida, em épocas mais úmidas, o intemperismo químico é mais forte e ocorre a verticalização da paisagem, com dissecação do relevo. Vale lembrar as propriedades geomorfológicas das rochas, ou seja, a erosão (seja física ou química) depende da natureza das rochas (suas propriedades físicas e químicas), desse modo, as paisagens são também frutos de uma erosão diferencial.

De acordo com Valadão (1998) o Brasil está totalmente inserido na Plataforma SulAmericana cujo embasamento foi consolidado no início do Fanerozoico, quando adquiriu estabilidade e passa a se comportar como uma unidade cratônica. No entanto, os eventos significativos para a área de estudo tiveram início com o Ciclo Brasiliano e Hasui (2012) argumenta que esse ciclo teve início no Neoproterozoico, por ocasião da fragmentação do supercontinente Rodínia. Dessa fragmentação foram formados novos microcontinentes, os quais constituiram os crátons Amazônico, São Francisco e São Luís, todos cercados por oceanos. Ainda no Neoproterozoico esses crátons passaram por uma colisão que culminou com a formação de áreas dobradas, denominadas de cinturões orogênicos (Mantiqueira, Tocantins e Borborema) e com a formação de um novo supercontinente, o Gondwana (Figura 2).

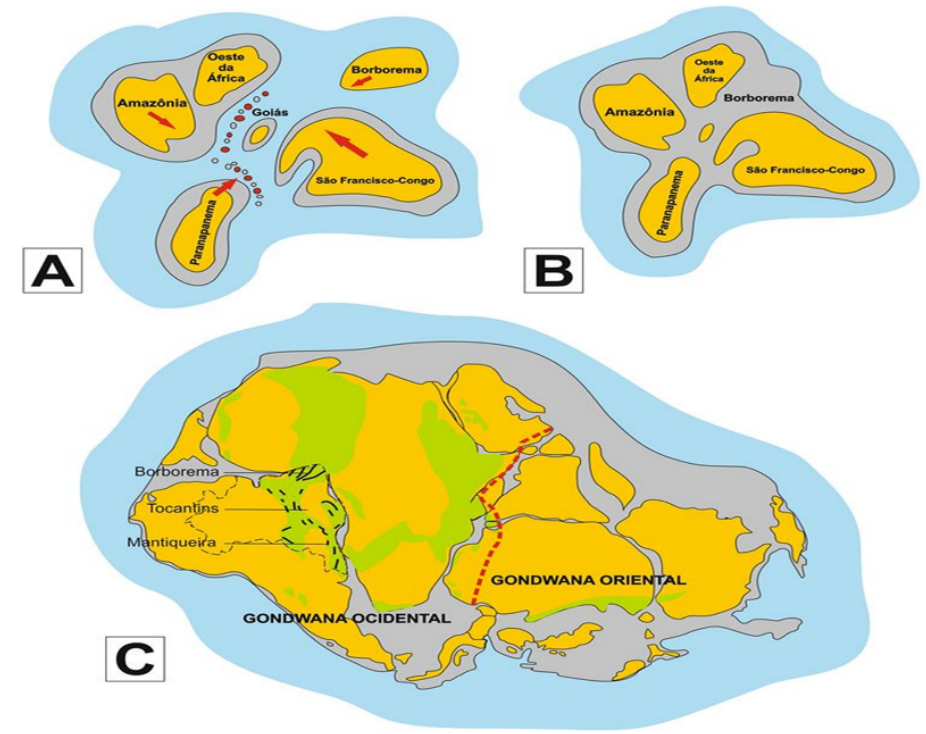

Figura 2: Bloco diagrama ilustrando o processo de formação do Gondwana: A- Pequenos continentes resultantes da separação do Rodínia, B- Esses continentes voltam a se aglutinar e formar um novo supercontinente, C- Formação do Gondwana e dos cinturões orogenéticos pela aglutinação dos microcontinentes derivados da separação do Rodínia.

Fonte: adaptado de Hasui, 2010, p. 145.

Moraes e Seer (2015) explicam que a aglutinação desses crátons fez com que porções da crosta terrestre fossem rasgadas na forma de grandes blocos de terra que avançaram uns sobre os outros, gerando os dobramentos. Essas faixas de dobramentos não são o único resultado dessa colisão. Simões (1995) argumenta que o Ciclo Brasiliano foi marcado por seis fases de deformação, as quais imprimiram 
marcas, tais como xistosidade, foliação, veios e fraturas, falhas e zonas de cisalhamento. Além disso, como essas porções da crosta estavam cercadas por oceanos, os recifes, areias e as argilas que recobriam as praias e plataformas marinhas, ao serem dobradas, foram submetidas a elevadas temperaturas e pressões, se transformando em rochas metamórficas, a maioria, do tipo quartzitos, filitos e xistos (Moraes, Seer, 2015). Todas essas deformações fizeram com que o Sistema Orogênico do Tocantins se transformasse numa província geotectônica de grande complexidade (Saadi, 1991).

Na área de estudo há o predomínio do Sistema Orogênico Tocantins, o qual pode ser subdividido em três áreas: Cinturão Brasília, Cinturão Araguaia e o Cinturão Paraguai. Hasui (2012) considera que todo o Cinturão Brasília foi afetado pelos processos colisionais do Ciclo Brasiliano e que a deformação originada pode ser traduzida em dobramentos e segmentação de lascas (nappes) por falhas de empurrão. Nos casos de convergência frontal ou colisão de baixa obliquidade, além das falhas de empurrão, desenvolvem-se rampas laterais e oblíquas, e falhas transcorrentes (Hasui, 2010).

A Faixa Brasília faz parte do Cinturão Brasília e corresponde a uma faixa de dobramentos que se estende por aproximadamente 1000 quilômetros na direção N-S dos estados de Minas Gerais, Goiás, Distrito Federal e Tocantins (Bento, 2018). De acordo com Uhlein et al. (2012) a Faixa Brasília apresenta um gradiente metamórfico invertido, variando da fácies xisto verde (domínio externo) a anfibolito superior (domínio interno). Segundo os autores supracitados, a presença de rochas de baixo metamorfismo por baixo de rochas de elevado grau metamórfico sugere que as inversões tectônicas ocorreram após o auge do metamorfismo.

Essa faixa é dividida por um importante lineamento denominado Megainflexão dos Pirineus em Faixa Brasília Meridional (FBM) e Faixa Brasília Setentrional (Silva et al., 2012). A FBM é constituída por unidades sedimentares e metassedimentares com deformação tectônica e aumento no grau metamórfico de leste para oeste e é subdividida em zonas cratônica (embasamento coberto pelas sequências sedimentares proterozoicas dos grupos Paranoá e Bambuí), interna (rochas do Grupo Araxá e de áreas de embasamento expostas entre os xistos), e externa (sequências metassedimentares dos grupos Paranoá, Canastra, Vazante e Ibiá), respectivamente de leste para oeste. Os grupos Canastra, Ibiá, Araxá e Vazante estão envolvidos em um complexo sistema de nappes e o contato entre as várias unidades envolve zonas de cisalhamento de baixo ângulo com forma arqueada de dobras em bainha desenvolvendo rampas laterais de cisalhamento (Andrade, 2012).

Os relevos serranos da Serra da Canastra fazem parte da FBM e as litologias que caracterizam essa área são representadas pelo Grupo Canastra (Nazar, 2018) (Figura 3). Silva et al. (2012) argumentam que, devido a intensa deformação, a estratigrafia desse grupo não é complementamente compreendida e, para fins deste trabalho, optou-se em usar a estratigrafia proposta por Simões et al. (2005). A justificativa é que são os responsáveis pelo mapeamento geológico da Folha Vargem Bonita (1:100.000), realizado no âmbito do Projeto Fronteiras de Minas Gerais e que 
englobou os municípios de São Roque de Minas, Vargem Bonita, Bambuí e Piumhi, Medeiros, São João Batista do Glória e Delfinópolis, a maioria pertencente a área de estudo.
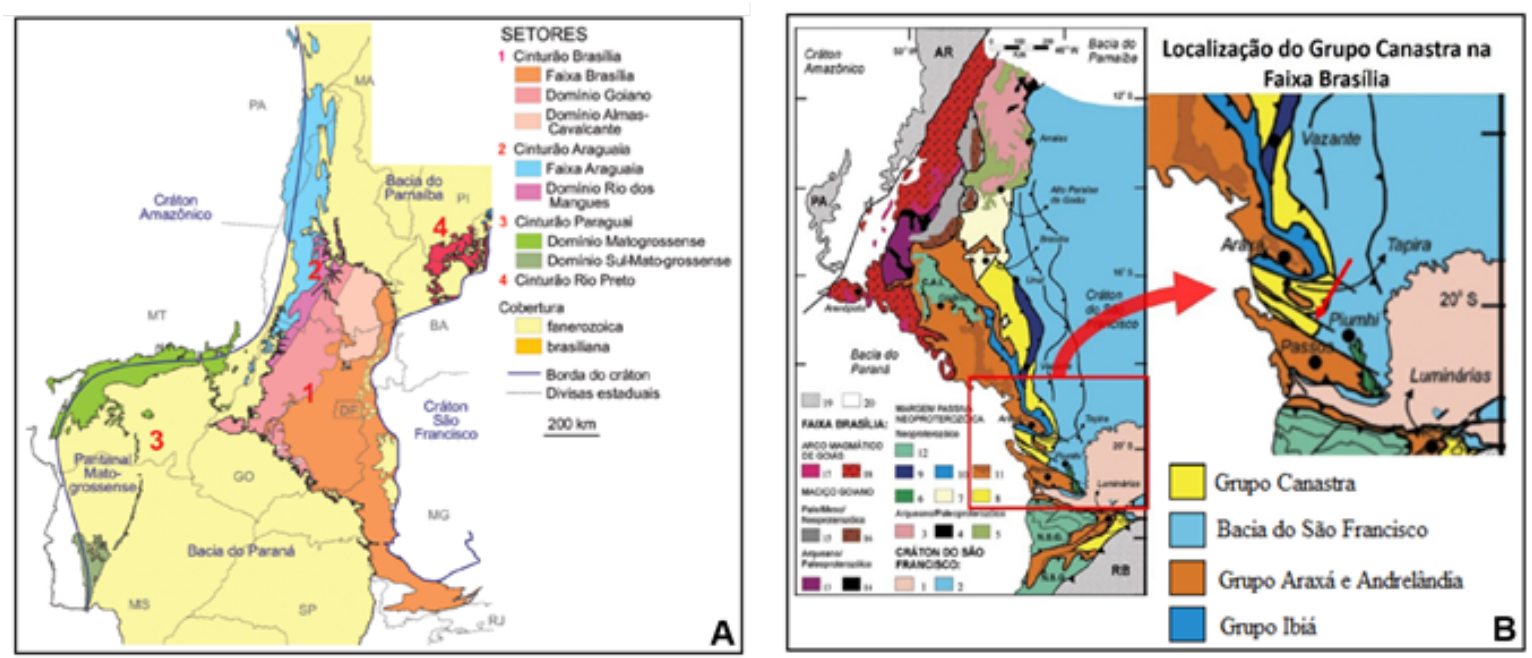

Figura 3: Mosaico sobre a Província Tocantins: A- Setores da província e B- Localização do grupo Canastra na Faixa Brasília.

Fonte: A- Hasui, 2012 e B- Valeriano et al., 2004.

O termo "grupo Canastra" foi primeiramente usado em 1970 por uma equipe de geólogos liderada por Otávio Barbosa para indicar o conjunto de rochas predominantemente arenosas encontradas na serra homônima (Moraes, Seer, 2015). Silva et al. (2012) explicam que as litologias associadas a esse grupo são rochas metamórficas de baixo grau, comumente quartzitos e filitos, que ocorrem em uma faixa contínua entre o Sudoeste de Minas Gerais e o Oeste e Centro de Goiás, mostrando grande complexidade tectônica e estratigráfica. Os sedimentos que deram origem a esse grupo, antes de passarem pelo processo de metamorfismo em função do Ciclo Brasiliano, estão associados a uma margem passiva na borda oeste do Cráton São Francisco que se tornou palco de sedimentação entre a segunda metade do Mesoproteroizo e início do Proterozoico (Nazar, 2018).

Simões et al. (2005) dividem o Grupo Canastra em unidades formais (Subgrupos Chapada dos Pilões e Paracatu) e o Canastra indeterminado. No entendimento dos autores supracitados, o conjunto mais a norte da Serra da Canastra reúne litologias correlacionadas às unidades formais do Grupo Canastra (Subgrupos Chapada dos Pilões e Paracatu) e para os conjuntos central e sul não há indicações seguras que permitam a correlação com as unidades formais do Grupo Canastra, sendo, por isso, atribuídos ao Grupo Canastra Indeterminado. Esses três conjuntos litológicos são separados entre si por zonas de cisalhamento de alto ângulo que correspondem a rampas laterais e/ou falhas direcionais.

Chaves, Benitez e Andrade (2012) descrevem que os quartzitos são predominantes na área, têm coloração branca e granulação fina, com intercalações métricas locais de filitos. Esses quartzitos variam de puro a micáceo, apresentando camadas de 
espessuras variadas, podendo ser maciças ou laminadas (Figura 4 A). A principal estrutura associada a essas rochas é uma foliação do tipo clivagem ardosiana, isto é, em metamorfismo de baixo grau (Figura 4 B) e, no caso de pressão do tipo dirigida (Figura $4 \mathrm{C}$ ), os minerais se recristalizam segundo planos preferenciais. As micas, por exemplo, formam planos de fraqueza na direção perpendicular aos esforços e, geralmente, os quartzitos micáceos, com esse tipo de clivagem, são mais frágeis e apresentam a propriedade de se desagregarem em placas (Thomé Filho, Moraes, Feijó de Paula, 2012).
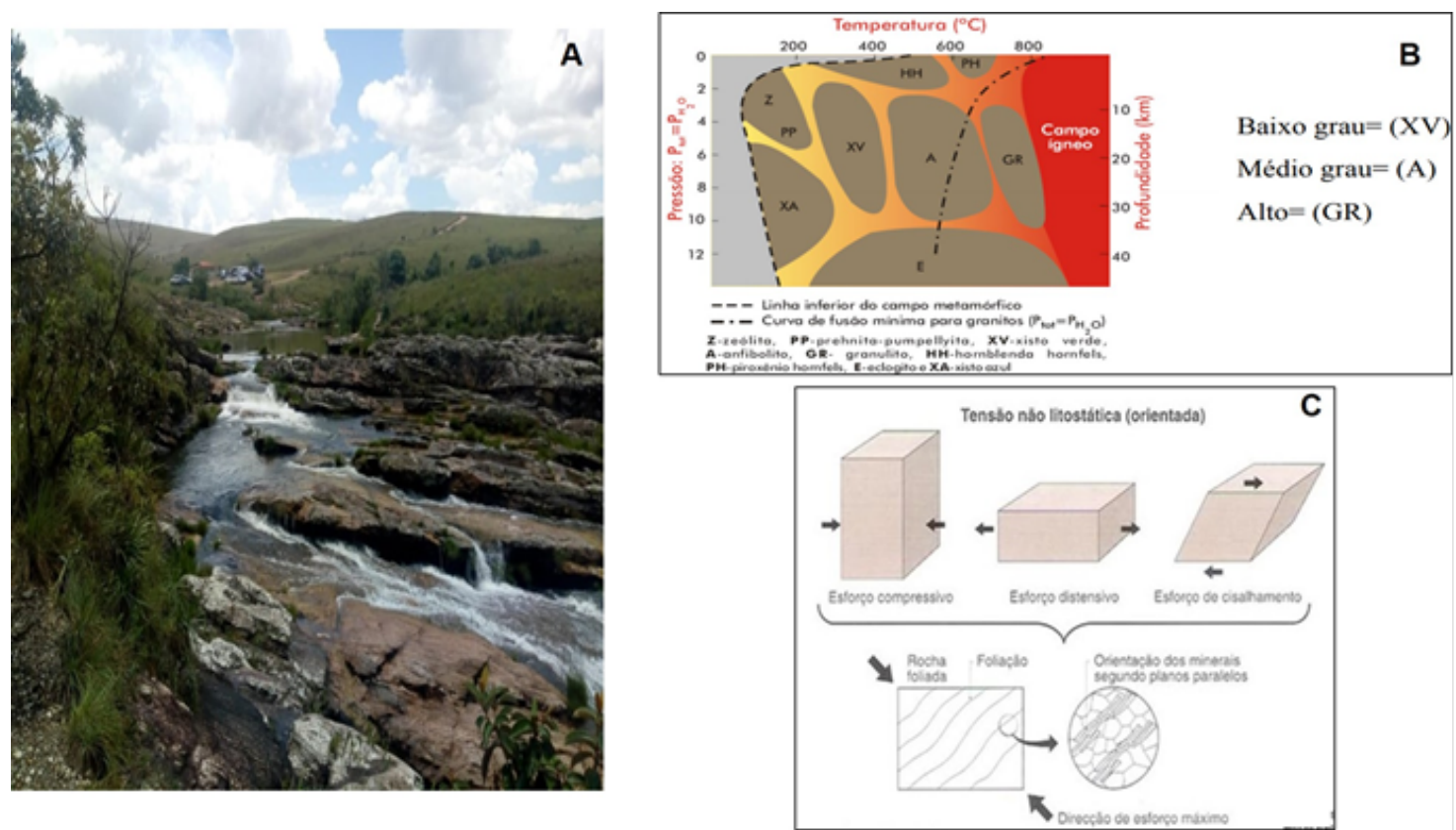

Figura 4: Mosaico com algumas características do quartzito encontrado na área de estudo: AFolição e mergulho, B- Graus de metamorfísmo e C- Foliação por esforço compressivo.

Fonte: B- Teixeira et al., 2003, p. 392 e C- Imagem disponível em: https://www.tulane.edu/ sanelson/eens212/metatexture.htm

Após o Proterozóico, quando ocorreu o evento Brasiliano, iniciou-se o Ciclo tectônico atual, a partir do siluriano, subdividido em duas etapas, a de Estabilidade e a de Ativação Mesozoica (Figura 5). A primeira é marcada por um período de calmaria tectônica com mudança no padrão de sedimentação. Silva et al. (2008) argumentam que nessa época os processos extensionais atuaram no sentido de originar as regiões rebaixadas, permitindo o desenvolvimento de bacias deposicionais (sinéclises), como as bacias do Parnaíba, Amazonas e do Paraná. Já a segunda está relacionada com a separação do Gondwana e abertura do Oceano Atlântico, culminando com manifestações básicas (derrames de basaltos e diques de diabásio) e alcalinas, intrusões de kimberlitos, bem como soerguimentos e sistemas de riftes (Carneiro et al., 2012). 


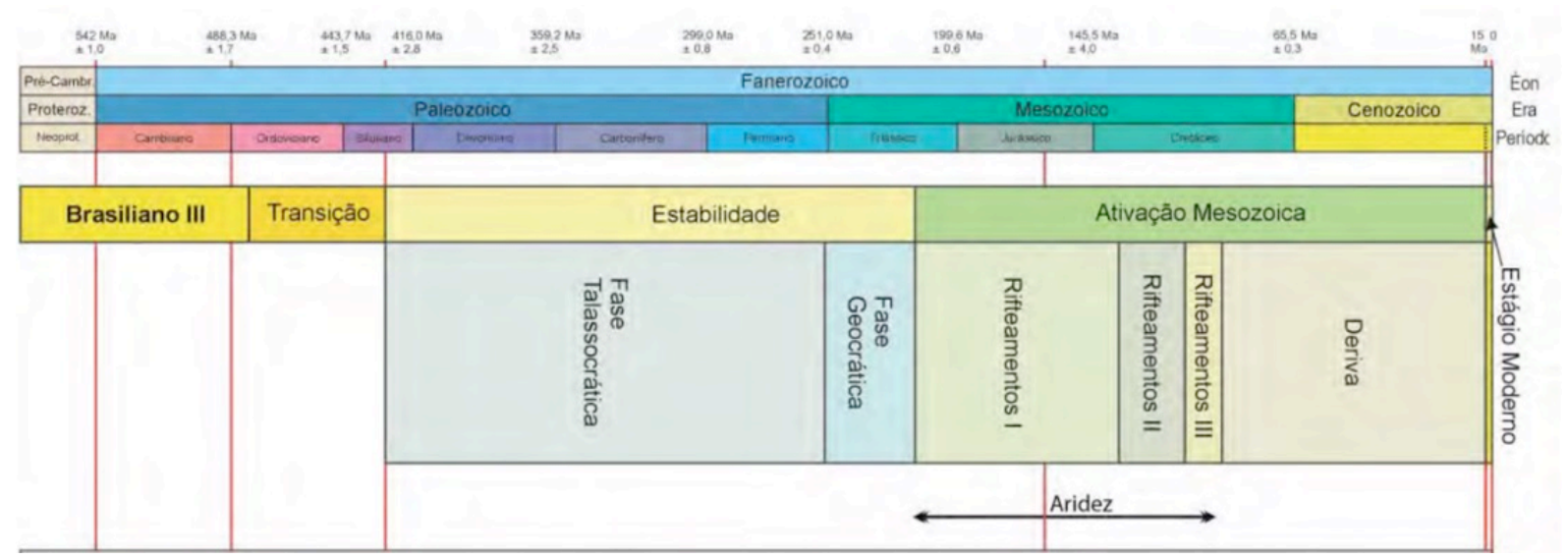

Figura 5: Estágios da evolução tectônica do Brasil durante o Fanerozoico.

Fonte: Carneiro et al., 2012, p. 133.

O novo contexto geológico associado com a separação da América do Sul e da África fez com que antigas fraturas existentes no território brasileiro fossem reativadas, além de gerar outras e, na área de estudo, além de influenciar na rede de drenagem, gerando cânions e as quedas d'água, essas feições também se transformaram numa saída mais fácil para um magma de importância geológica, no caso formando as reservas de diamantes. Referente à rede de drenagem, considerando-se a conformação estrutural da área, verifica-se que há dois padrões de controle dos lineamentos principais de drenagens: o primeiro coincide com as estruturas geológicas paralelas aos contatos entre xistos e quartzitos, geralmente associados aos traços de drenagem NW/SE. Já os alinhamentos coincidentes às juntas, ocupam as direções ortogonais às calhas de drenagem principais, como tributários de primeira ordem, preferencialmente, nas direções NE/SW (MMA/IBAMA, 2005).

A América do Sul continua a se afastar do continente africano até os dias atuais, tendo se individualizado totalmente no final da era Mesozoica e, desde então, o território mineiro, segundo Alkmin (2018), tem passado por grandes variações climáticas e um processo de erosão que continua até os dias atuais. Alvarenga et al. (2018) corroboram tal fato explicando que, após o evento brasiliano, a região da Serra da Canastra passou por períodos de calmaria tectônica alternados por soerguimentos durante o Mesozoico e início do Cenozoico e que a fisionomia atual resulta dos processos erosivos e intempéricos desde então. Saadi (1991) completa que o topo aplainado da Serra da Canastra é correlacionado à Superfície Sul Americana, uma vez que após a sedimentação Cretácea desenvolveu-se uma extensa superfície de erosão (Paleógena). E, como resultado dos processos de alteração e oxidação das rochas superficiais, gerados pelos agentes exógenos a partir, principalmente, do Cenozoico, é possível encontrar as formações mais recentes, as coberturas detríticolateríticas, constituídas, no geral, por cascalho, areia, argila e óxidos e hidróxidos de ferro (Moraes, Seer, 2015).

Do ponto de vista geomorfológico, Ross (2006) considera que a Serra da Canastra se insere na Morfoestrutura dos Planaltos e Serras de Goiás-Minas, estando associada, como já retratado acima, com os dobramentos da Faixa Brasília e com os processos 
de aplainamento a partir do Cenozoico, os quais geraram as serras residuais das antigas dobras com alinhamento de cristas sustentadas por rochas metamórficas, principalmente, quartzitos. Compreende, portanto, um conjunto de serras e chapadas que são divididas em dois grandes chapadões: Canastra (amplo platô localizado na área regularizada do parque) e Babilônia (constituído por relevo mais movimentado e dissecado com ocorrência de vales fluviais, na área ainda não regulamentada) (MMA/IBAMA, 2005). Localmente o Chapadão da Canastra pode ser subdivido em Chapadão do Diamante e da Zagaia - (Figura 6).

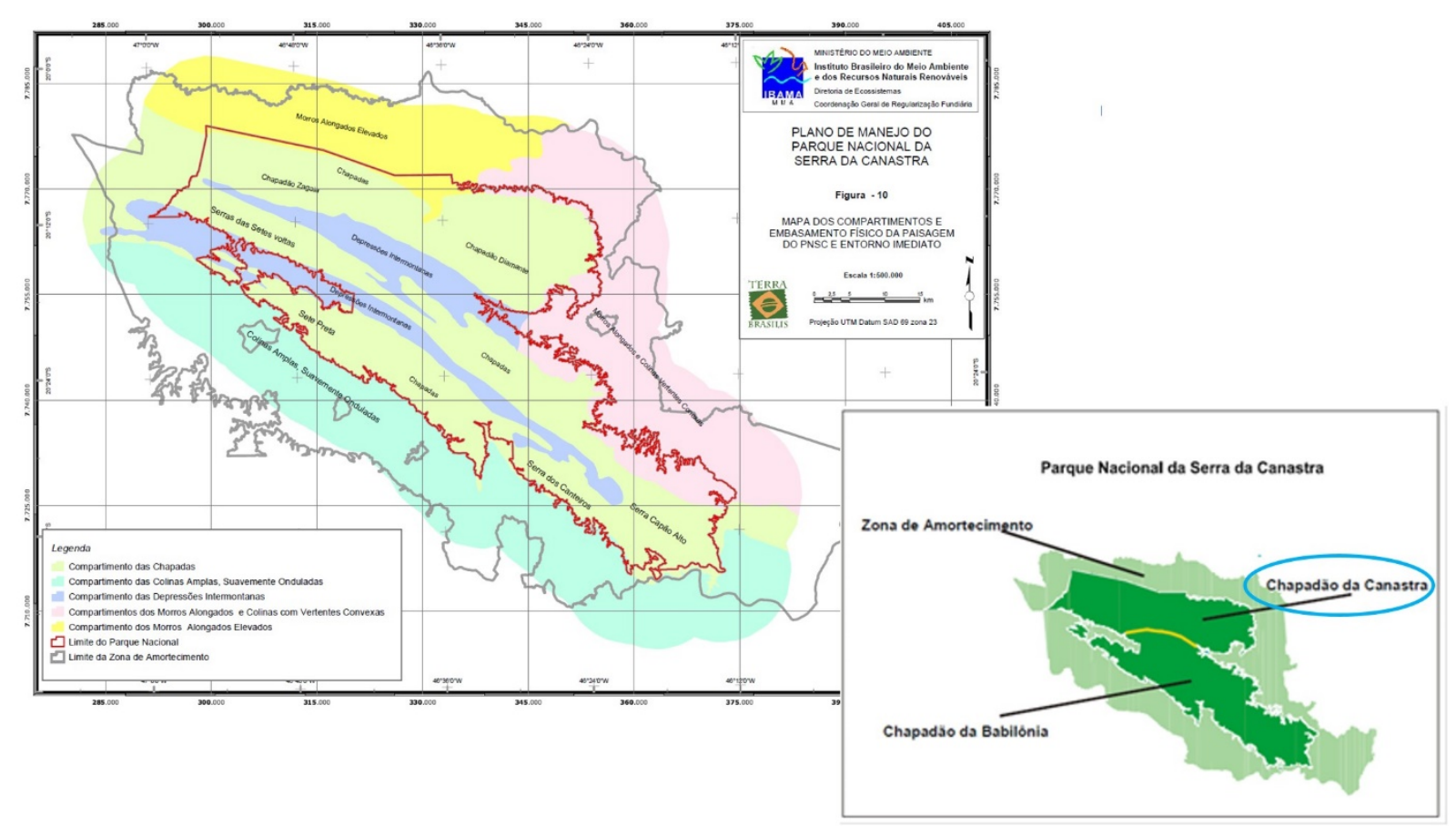

Figura 6: Em primeiro plano, delimitação do PARNA Serra da Canastra em dois chapadões principais e, ao fundo, o mapa dos compartimentos e embasamento físico do parque.

Fonte: adaptado de MMA/IBAMA, 2005, p. 2 e 110.

As chapadas são sustentadas por rochas mais resistentes, em geral quartzitos, enquanto que os vales foram esculpidos em rochas de menor resistência aos processos erosivos e se encontram encaixados nas zonas de fraqueza, as fraturas e falhas (Figura 7 A). No trabalho "O Chapadão do Diamante na Serra da Canastra/MG, Brasil: caracterização geomorfológica e análise integrada do meio físico a partir de dados multifontes", Nazar (2018) aponta que as chapadas, do setor leste da Serra da Canastra podem, ainda, ser compartimentadas em seis padrões de relevo, destacando-se, da área central para as bordas: i- relevo suavemente dissecado, iicristas quartzíticas e iii- escarpas (Figura 7 B). 


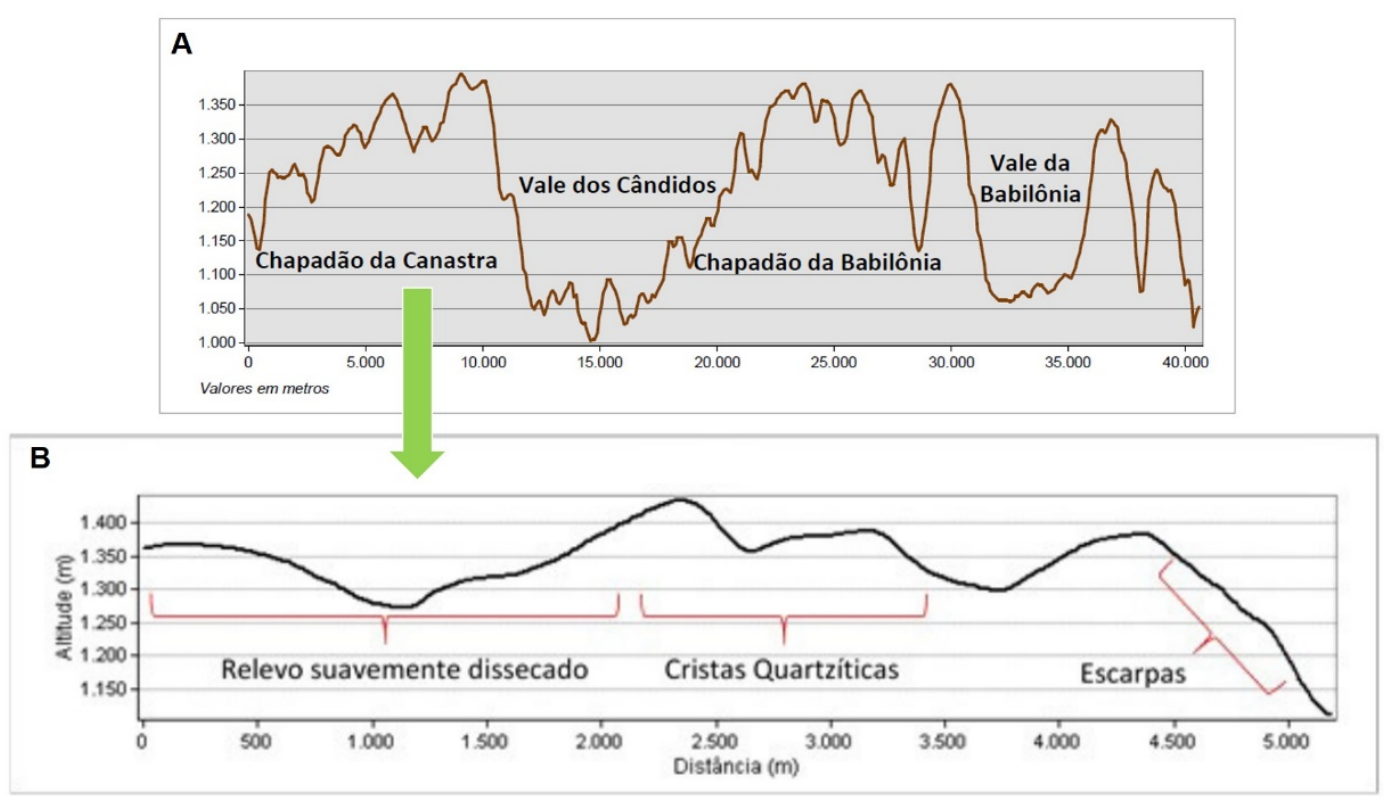

Figura 7: Perfil topográfico do PNSC: A- Perfil de todo o parque e B- Perfil do Chapadão do Diamante.

Fonte: Santos, 2014, p. 50 e B- Nazar, 2018, p. 140.

O primeiro compartimento, de acordo com a autora supracitada, aparece nas áreas adjacentes aos topos planos, principalmente na região central e NW do Chapadão do Diamante, caracterizando uma transição de relevo suave em direção aos fundos dos vales. O segundo, correlacionado aos afloramentos quartzíticos, compreende as maiores cotas altimétricas e, principalmente, feições rochosas peculiares, com grande quantidade de afloramentos de quartzitos, os quais desenvolvem uma camada superficial incipiente e cobertura vegetal composta por campos rupestres. A densidade de drenagem não é elevada, mas possui características estruturais marcantes, com lineamentos e grandes massas rochosas aflorantes, sendo estas as características principais para delimitar este padrão de relevo na área. E, por fim, o compartimento das escarpas apresenta papel especial neste trabalho por corresponder às áreas onde a maioria das quedas d'água do parque são encontradas. Esse padrão de relevo corresponde às feições que delimitam a chapada da área do entorno. Tendem a apresentar declives, em média, superiores a $45^{\circ}$, podendo chegar a alcançar a marca de $58^{\circ}$ de inclinação. São formas de relevo abruptas, caracterizadas por súbitas rupturas de declive, formando paredões rochosos exuberantes. Além disso, podem ser observados os depósitos de talude no sopé dessas áreas, com destaque para blocos rochosos de tamanhos variados depositados na base da cachoeira Casca D'Anta (Figura 8). 

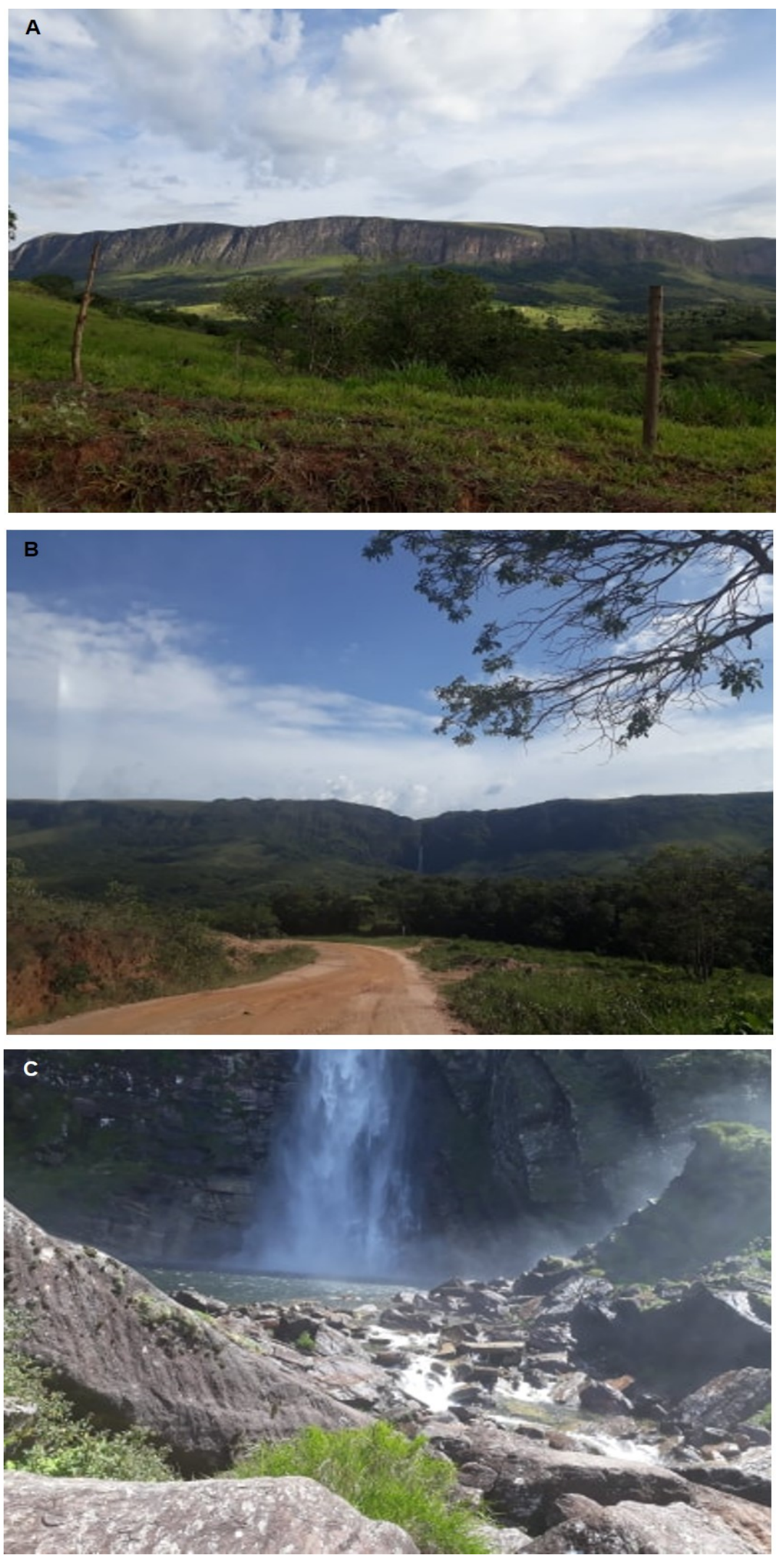

Figura 8: Mosaico com características do compartimento das escarpas: A- Chapadão do Diamante ao fundo, com paredões íngremes e sustentado por quartzitos puros, B- Cachoeira de Casca D'Anta, no compartimento das escarpas e C- Blocos rochosos encontrados no sopé da cachoeira citada. 
De modo geral, pode-se dizer que a área de estudo está localizada na Faixa Brasília, área de dobramentos resultantes do evento brasiliano. É composta por lineamentos de direção NW-SE marcados por falhas normais e de empurrão, além de litologias diferentes e que se comportam de forma distinta aos processos denudacionais. $\mathrm{E} o$ resultado de tal realidade pode ser visto no relevo, uma sequência de planaltos e serras com níveis altimétricos elevados gerados pelas camadas de quartzitos, e as depressões, estas últimas formadas devido à incisão dos cursos d'água ao longo das zonas de fraqueza (fraturas e falhas) e da menor resistência das rochas (Mauro, Valadão, 2018) - (Figura 9).

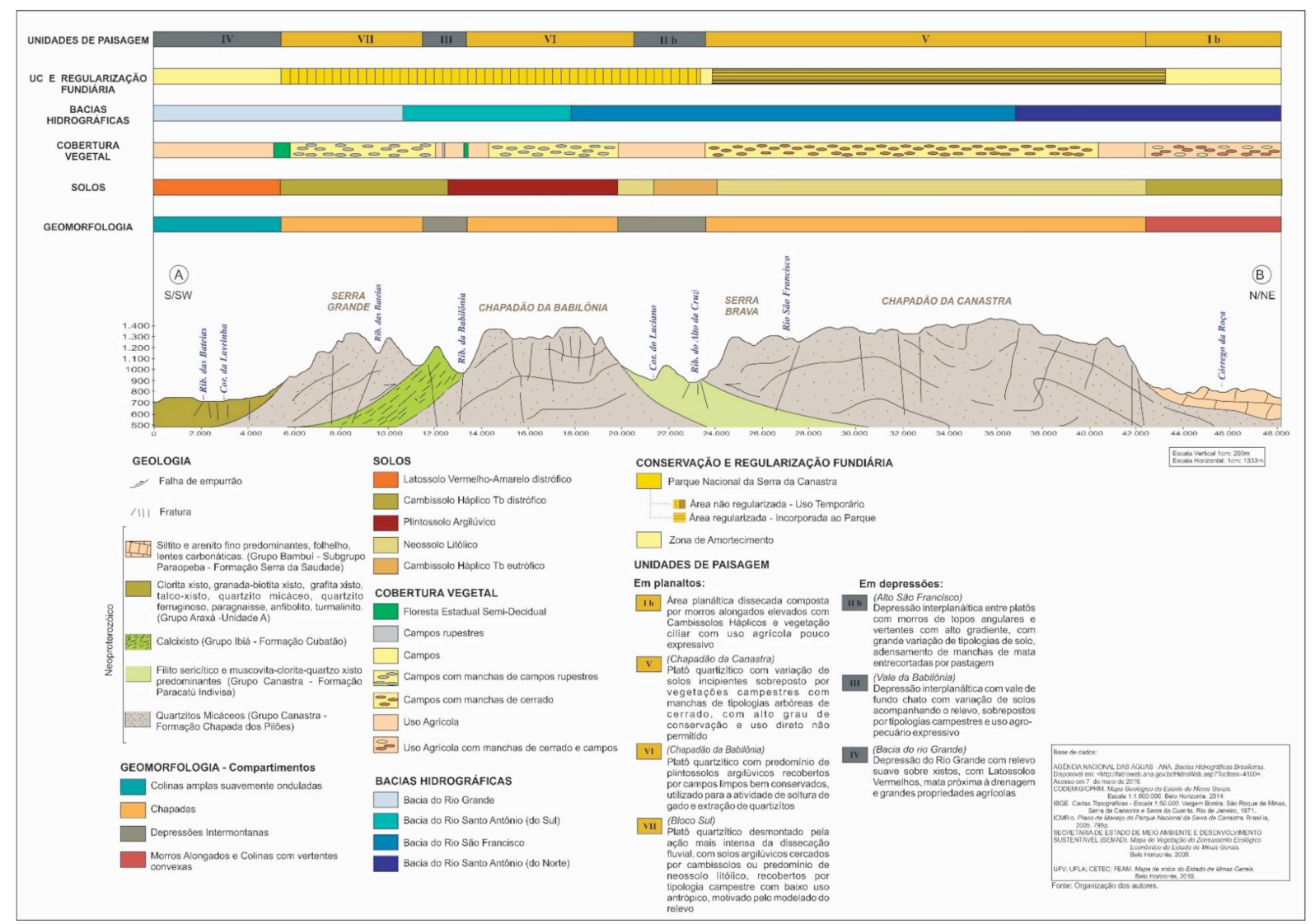

Figura 9: Estruturação vertical da paisagem do PNSC, segundo seção regional sudoeste-nordeste. A Cachoeira da Casca D'anta aparece no Chapadão da Canastra, na unidade V.

Fonte: Mauro; Valadão, 2018, p. 66.

\section{Conclusões}

O objetivo deste trabalho foi apresentar um levantamento científico dos aspectos geológicos e geomorfológicos, de modo a compreender a origem e evolução da Cachoeira de Casca D'anta, localizada dentro do PARNA Serra da Canastra. Esse foi o primeiro passo na direção de se buscar o aproveitamento geoturístico dessa queda mediante a proposição de painéis interpretativos, esta sendo a perspectiva futura dos autores. 
Através da metodologia utilizada foi possível atingir o objetivo proposto e concluir que essa queda está inserida numa região de grande complexidade litológica e estrutural e que, como indica o título do artigo "Serra da Canastra: de mar a montanha", de autoria de Moraes e Seer (2015), já passou por grandes transformações ao longo do tempo geológico e hoje se traduz numa paisagem de grande beleza cênica e importância ecológica.

Em virtude das unidades litológicas presentes no parque e suas propriedades geomorfológicas distintas, a região comporta diversos tipos de solo e relevo e estes acabam influenciando no surgimento de ambientes variados, inclusive, com a ocorrência de espécies da fauna e flora endêmicos dessa região. Todo esse cenário atrai o olhar de visitantes de diversas localidades e fomenta a necessidade de aproveitar essa visitação para promover o entendimento dos lugares, propósito principal do geoturismo.

Tal necessidade se faz presente, pois mesmo estando situada no interior de uma unidade de conservação que prevê a visitação, não possui nenhum instrumento voltado ao conhecimento geocientífico e, nesse sentido, ocorre uma lacuna do ponto de vista do conhecimento. Os visitantes conhecem o parque, se deslumbram com a paisagem, mas saem sem entender a formação e evolução dessa paisagem e, muito menos, qual o real valor desses lugares.

O PARNA Serra da Canastra possui os pilares fundamentais para a prática do geoturismo: a) atrativos ligados ao geopatrimônio, b) infraestrutura básica e c) visitantes; a lacuna existente é justamente do ponto de vista da informação, falta o investimento em ações voltadas à valorização e divulgação da geodiversidade, para que os visitantes percebem que o parque tem outros atributos e importância além da beleza cênica, tais como os serviços ambientais.

A partir do levantamento aqui exposto e da compreensão gerada da área de estudo os autores reunirão esforços no sentido de fazer a proposição de painéis interpretativos sobre a Cachoeira de Casca D'anta, contribuindo com os programas de educação e interpretação ambiental dessa unidade de conservação. Espera-se dar um passo importante rumo a valorização e divulgação da Geodiversidade e que, a partir da visitação e entendimento dessa queda, os visitantes se mobilizem e cobrem pela proteção de outras áreas que ainda não estão protegidas e que também apresentem algum tipo de valor e/ou serviço ambiental.

\section{Financiamento}

Este trabalho apresentou alguns resultados da pesquisa financiada pela FAPEMIG PROJ. CRA 0231/2016.

\section{Bibliografia}

Andrade, K. W. (2012). Química de minerais indicadores de intrusões kimberlíticas com ênfase na província diamantifera Serra da Canastra (MG): importância na prospecção de intrusões férteis. Dissertação de Mestrado em Geologia, UFMG, Belo Horizonte. 
Alkmin, F. F. (2018). História geológica de Minas Gerais. In: Pedrosa-Soares, A. C., Voll, E., Cunha, E. C. (Orgs.). Recursos minerais de Minas Gerais On Line: síntese do conhecimento sobre as riquezas minerais, história geológica, e meio ambiente e mineração de Minas Gerais. (pp. 1-37). Belo Horizonte, CODEMGE.

Alvarenga, L. J., Castro, P. de T. A., Bernardo, J. M., Campos, I. C. de (2018). Paisagem Cultural e Geoconservação: Contributos Conceituais Aplicados na Serra da Canastra, Brasil. Anuário do Instituto de Geociências, 41(2), 241-251. http://dx.doi.org/10.11137/2018 2241251

Bento, L. C. M. (2010). Potencial geoturístico das quedas d'água de Indianópolis. Dissertação de Mestrado em Geografia, Universidade Federal de Uberlândia, Uberlândia.

Bento, L. C. M. (2014). Parque Estadual do Ibitipoca/MG: potencial geoturístico e proposta de leitura do seu geopatrimônio por meio da interpretação ambiental. Tese de Doutorado em Geografia, Universidade Federal de Uberlândia, Uberlândia.

Bento, L. C. M. (2018). Alguns apontamentos sobre os aspectos geológicos da Mesorregião do Triângulo e Alto Paranaíba (Minas Gerais). In: Portuguez, A. P., Sobrinho, L. A. (Orgs.). Inquietações geográficas: natureza, sociedade e turismo no Brasil contemporâneo. (pp. 6389). Ituiutaba, Barlavento

Bento, L. C. M., Rodrigues, S. C. (2013). Geoturismo em unidades de conservação. Revista do Departamento de Geografia, 25, 77-97. https://doi.org/10.7154/RDG.2013.0025.0005

Bizerril, M., Soares, C. C., Santos, J. P. (Orgs.). (2008). Um lugar chamado Canastra. Atibaia: Instituto Pró-carnívoros.

Boas, G. H. V., Marçal, M. dos S. (2014). Geologia e estudo da paisagem aplicados ao turismo. In: Aranha, R. de C., Guerra, A. J. T. (Orgs.). Geografia aplicada ao turismo. (pp. 81-116). São Paulo, Oficina de Textos.

Brilha, J. (2005). Patrimônio geológico e geoconservação - a conservação da natureza na sua vertente geológica. Braga: Palimage.

Carcavilla, L., Durán, J. J., López-Martinez, J. (2008). Geodiversidad: concepto y relación com el patrimônio geológico. In: Anais do Congresso Geológico de España, 7. (pp. 1299-1303). Las Palmas de Gran Canaria: [s.I].

Carneiro, C. D. R., Almeida, F. F. M. de, Hasui, Y., Zalán, P. V., Teixeira, J. B. G. (2012). Estágios evolutivos do Brasil no Fanerozoico. In: Hasui, Y., Carneiro, C. D. R., Almeida, F. F. M. de, Bartorelli, A. (Orgs.). Geologia do Brasil. (pp. 131-137). São Paulo, Beca.

Chaves, M. L. de S. C., Benitez, L., Andrade, K. W. (2009). Cachoeira de Casca D’Anta, São Roque de Minas, MG. In: Winge, M. (Ed.). Sítios geológicos e paleontológicos do Brasil, $v$. II. (pp. 151-162). Brasília, CPRM.

Gray, M. (2005). Geodiversity and Geoconservation: what, why, and how? Geodiversity \& Geoconservation, 4-12. http://www.georgewright.org/223gray.pdf

Gray, M. (2011). Other nature: geodiversity and geosystem services. Environmental Conservation, 38(3), 271-274. https://doi.org/10.1017/S0376892911000117

Hasui, Y. (2012). Sistema Orogênico Tocantins. In: Hasui, Y., Carneiro, C. D. R., Almeida, F. F. M., Bartorelli, A. Geologia do Brasil. (pp. 289-330). São Paulo, Beca. 
Hasui, Y. (2010). A grande colisão pré-cambriana do Sudeste brasileiro e a estruturação $\begin{array}{lll}\text { regional. } & \text { Geociências, } & \text { 29(2), }\end{array}$ http://www.ppegeo.igc.usp.br/index.php/GEOSP/article/view/7147

King, L. C. (1956). A Geomorfologia do Brasil Ocidental. Revista Brasileira de Geografia, 18(2), 147-265. Disponível em: https://biblioteca.ibge.gov.br/visualizacao/periodicos/115/rbg 1956 v18 n2.pdf

Mauro, M. F., Valadão, R. C. (2018). Organização estrutural da paisagem da Serra da Canastra (MG). Sociedade e Natureza, 30(1), 53-79. https://doi.org/10.14393/SN-v30n12018-3

MMA/IBAMA. (2005). Plano de Manejo da Serra da Canastra. Disponível em: http://www.icmbio.gov.br/portal/images/stories/imgs-unidades coservacao /PM PNSC Resumo Executivo.PDF

Moraes, L. C. de, Seer, H. J. (2015). Serra da Canastra: de mar a montanha. Ciência Hoje, 55(328), 25-29.

Nazar, T. I. S. M. O (2018). Chapadão do Diamante na Serra da Canastra/MG, Brasil: caracterização geomorfológica e análise integrada do meio físico a partir de dados multifontes. Tese de Doutorado em Geografia, Universidade Federal de Uberlândia, Uberlândia.

Penteado, M. M. (1993). Fundamentos de Geomorfologia. 3 ed. Rio de Janeiro, IBGE.

Ross, J. L. S. (2006). Ecogeografia do Brasil: Subsídios para planejamento ambiental. São Paulo, Oficina de Texto.

Saadi, A. (1991). Ensaio sobre a morfotectônica de Minas Gerais. 1991. Tese para Professor Titular, Universidade Federal de Minas Gerais, Belo Horizonte.

Saint-Hilaire, A. de (1975). Viagem as Nascentes do Rio São Francisco. São Paulo: EDUSP; Belo Horizonte, Itatiaia.

Santos, A. A. (2014). Paisagem do Parque Nacional da Serra da Canastra e de sua zona de amortecimento - MG: análise de padrões espaciais a partir de árvore de decisão e métricas de paisagem. Dissertação de Mestrado em Geografia, Universidade Federal de Minas Gerais, Belo Horizonte.

Silva, C. H., Simões, L. S. A., Damázio, W. L., Ferreira, S. N., Luvizotto, G. L. (2012). O Grupo Canastra em sua área-tipo, região de Tapira, sudoeste do estado de Minas Gerais. Geologia USP, Série Científica, 12(2), 83-98. https://doi.org/10.5327/Z1519874X2012000200006

Silva, M. L. N. da, Mansur, K. L., Nascimento, M. A. L. do (2018). Serviços Ecossistêmicos da Natureza e sua Aplicação nos Estudos da Geodiversidade: uma Revisão. Anuário do Instituto de Geociências - UFRJ, 41(2), 699-709. http://dx.doi.org/10.11137/2018 2699709

Simões, L. S. A. (1995). Evolução tectono-metamórfica da Nappe de Passos, sudoeste de Minas Gerais. Tese de Doutorado em Geociências, USP, São Paulo.

Simões, L. S. A., Martins, J. E. S., Valeriano, C. M., Godoy, A. M., Artur, A. C. (2015). Folha Vargem Bonita, SF.23-V-B-I. Projeto Fronteiras de Minas Gerais. Programa Mapeamento Geológico do Estado de Minas Gerais. UFMG. 
Teixeira, W., Toledo, M. C.M. de, Fairchild, T. R., Taioli, F. (Orgs.). (2000). Decifrando a Terra. São Paulo: Oficina de Textos, 2000.

Tilden, F. (1957). Interpreting Our Heritage. EUA: University of North Carolina Press.

Thomé Filho, J. J., Moraes, J. M., Paula, T. L. F. de (2012). Geoparque Pireneus (GO) proposta. In: Schobbenhaus, C., Silva, C. R. da (Orgs.). Geoparques do Brasil-propostas. (pp. 110-150). Rio de Janeiro, CPRM.

Uhlein, A., Fonseca, M. A., Seer, H. J., Dardene, M. A. (2012). Tectônica da Faixa de Dobramentos Brasília - setores sententrional e meridional. Geonomos, 20(2), 1-14.

Valadão, R. C. (1998). Evolução de longo-termo do relevo do Brasil Ocidental (desnudação, superfícies de aplanamento e soerguimentos crustais). Tese de Doutorado em Geologia, Universidade Federal da Bahia.

Valeriano, C. M., Dardenne, M, A., Fonseca, M. A., Simões, L. S., Seer, H. J. (2004). A Evolução Tectônica da Faixa Brasília. In: Mantesso Neto, V., Bartorelli, A., Dal Ré Carneiro, C., Neves, B. B. (Org.) Geologia do Continente Sul-Americano: evolução da obra de Fernando Flávio Marques Almeida. (pp. 575-593). São Paulo, Editora Beca.

Vieira, A., Cunha, L. (2004). Património Geomorfológico - tentativa de sistematização. In: Actas do III Seminário Latinoamericano de Geografia Física, Puerto Vallarta. http://hdl.handle.net/1822/35546

Artigo recebido em/ Received on: 13/11/2019

Artigo aceite para publicação em/ Accepted for publication on: 30/12/2019 